$\rightarrow$ Tofactinib monotherapy -0 Tofacitinib + MTX

a) MDA
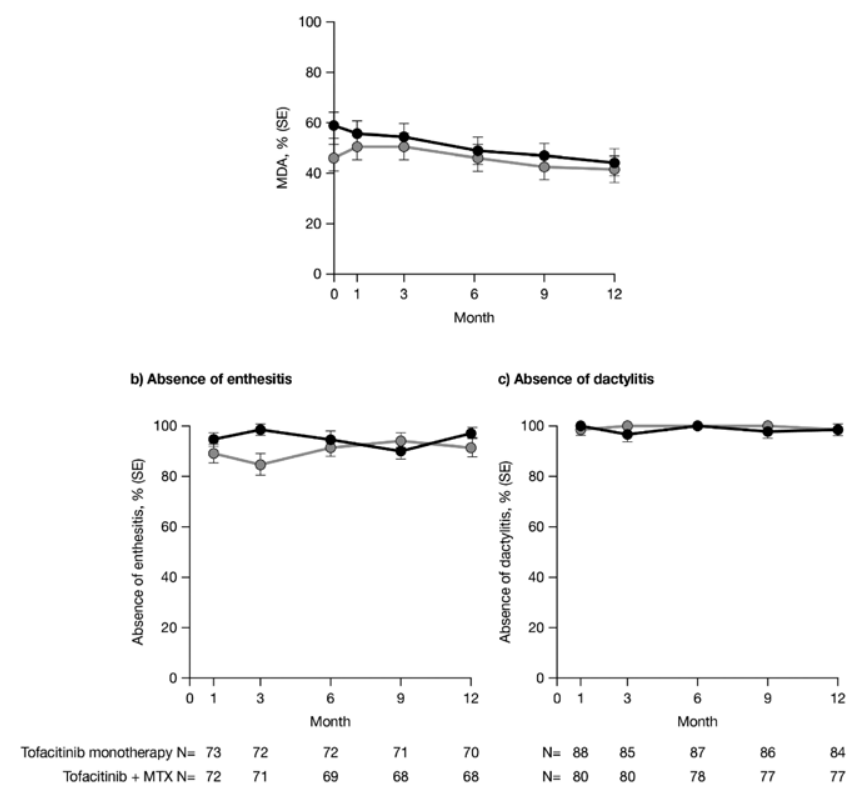

- Missing response=non-response. The numbers of patients included in this analysis were 90 and 89 for tofacitinib monotherapy and tofacitinib + MTX, respectively; " "n patients with Lel $=0$ at baseline, no imputation, " in patients win DSS 0 at baseline, no imputation

Table. Safety outcomes to Month 12

\begin{tabular}{|c|c|c|}
\hline $\begin{array}{l}\text { Pts with events, } n(\%) \text { AEs of } \\
\text { special interest }\end{array}$ & $\begin{array}{c}\text { Tofacitinib } \\
\text { monotherapy } \mathrm{N}=90\end{array}$ & $\begin{array}{c}\text { Tofacitinib + MTX } \\
\text { N=89 }\end{array}$ \\
\hline$A E$ & $43(47.8)$ & $41(46.1)$ \\
\hline Serious $\mathrm{AE}$ & $4(4.4)$ & $3(3.4)$ \\
\hline Discontinuations due to $\mathrm{AE}$ & $3(3.3)$ & $4(4.5)$ \\
\hline Death & 0 & 0 \\
\hline Herpes zoster (serious/non-serious) & $1(1.1)$ & $2(2.2)$ \\
\hline Serious infection & 0 & $2(2.2)$ \\
\hline Opportunistic infection $^{a}$ & 0 & $1(1.1)$ \\
\hline Malignancy $\left(\right.$ excl. NMSC) ${ }^{a}$ & $1(1.1)$ & $1(1.1)$ \\
\hline NMSC $^{a}$ & 0 & 0 \\
\hline Major adverse cardiovascular event ${ }^{\mathrm{a}}$ & 0 & 0 \\
\hline Venous thromboembolism ${ }^{\mathrm{C}}$ & 0 & 0 \\
\hline Arterial thromboembolism ${ }^{\mathrm{C}}$ & $1(1.1)$ & 0 \\
\hline Gastrointestinal perforation ${ }^{a}$ & 0 & 0 \\
\hline Interstitial lung disease ${ }^{\mathrm{b}}$ & 0 & 0 \\
\hline \multicolumn{3}{|l|}{ Laboratory parameters $^{d}$} \\
\hline ALT $\geq 3 \times U L N$ & 0 & $5(5.6)$ \\
\hline ALT (IU/L), mean (SE) & $-2.7(1.6)$ & $2.5(1.3)$ \\
\hline AST $\geq 3 \times$ ULN & 0 & $3(3.4)$ \\
\hline AST (IU/L), mean (SE) & $-1.5(1.2)$ & $1.7(0.8)$ \\
\hline
\end{tabular}

Reviewed by independent ${ }^{a}$ external $/{ }^{b}$ internal adjudication committee

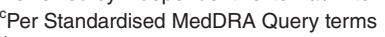

Without regard to baseline abnormality

ALT, alanine aminotransferase; AST, aspartate aminotransferase; ULN, upper limit of normal

Acknowledgments: Study sponsored by Pfizer Inc. Medical writing support was provided by Christina Viegelmann of CMC Connect and funded by Pfizer Inc.

Disclosure of Interests: Peter Nash Grant/research support from: AbbVie, Bristol-Myers Squibb, Celgene, Eli Lilly and Company, Gilead, Janssen, MSD, Novartis, Pfizer Inc, Roche, Sanofi, UCB, Consultant of: AbbVie, Bristol-Myers Squibb, Celgene, Eli Lilly, Gilead, Janssen, MSD, Novartis, Pfizer Inc, Roche, Sanofi, UCB, Speakers bureau: AbbVie, Bristol-Myers Squibb, Celgene, Eli Lilly, Gilead, Janssen, MSD, Novartis, Pfizer Inc, Roche, Sanofi, UCB, Laura C Coates: None declared, Philip J Mease Grant/research support from: Abbott, Amgen, Biogen Idec, BMS, Celgene Corporation, Eli Lilly, Novartis, Pfizer, Sun Pharmaceutical, UCB - grant/ research support, Consultant of: Abbott, Amgen, Biogen Idec, BMS, Celgene Corporation, Eli Lilly, Novartis, Pfizer, Sun Pharmaceutical, UCB - consultant, Speakers bureau: Abbott, Amgen, Biogen Idec, BMS, Eli Lilly, Genentech, Janssen, Pfizer, UCB - speakers bureau, Alan Kivitz Shareholder of: AbbVie, Amgen, Gilead, GSK, Pfizer Inc, Sanofi, Consultant of:AbbVie, Boehringer Ingelheim,,Flexion, Genzyme, Gilead, Janssen, Novartis, Pfizer Inc, Regeneron, Sanofi, SUN Pharma Advanced Research, UCB, Paid instructor for: Celgene, Genzyme, Horizon, Merck, Novartis, Pfizer, Regeneron, Sanofi, Speakers bureau: AbbVie, Celgene, Flexion, Genzyme,
Horizon, Merck, Novartis, Pfizer Inc, Regeneron, Sanofi, Dafna D Gladman Grant/ research support from: AbbVie, Amgen Inc., BMS, Celgene Corporation, Janssen, Novartis, Pfizer, UCB - grant/research support, Consultant of: AbbVie, Amgen Inc. BMS, Celgene Corporation, Janssen, Novartis, Pfizer, UCB - consultant, Frank Behrens Grant/research support from: Pfizer, Janssen, Chugai, Celgene, Lilly and Roche, Consultant of: Pfizer, AbbVie, Sanofi, Lilly, Novartis, Genzyme, Boehringer, Janssen, MSD, Celgene, Roche and Chugai, James Cheng-Chung Wei Grant/ research support from: AbbVie, Bristol-Myers Squibb, Celgene, Eli Lilly, Janssen, Novartis, Pfizer Inc, UCB, Consultant of: AbbVie, Bristol-Myers Squibb, Celgene, Chugai, Eisai, Janssen, Novartis, Pfizer Inc, Sanofi-Aventis, UCB Pharma, Dona Fleishaker Shareholder of: Pfizer Inc, Employee of: Pfizer Inc, Joseph Wu Shareholder of: Pfizer Inc, Employee of: Pfizer Inc, Cunshan Wang Shareholder of: Pfizer Inc, Employee of: Pfizer Inc, Ana Belen Romero Shareholder of: Pfizer Inc, Employee of: Pfizer Inc, Lara Fallon Shareholder of: Pfizer Inc, Employee of: Pfizer Inc, Ming-Ann Hsu Shareholder of: Pfizer Inc, Employee of: Pfizer Inc, Keith Kanik Shareholder of: Pfizer Inc, Employee of: Pfizer Inc

DOI: 10.1136/annrheumdis-2020-eular.529

\section{OP0226 \\ NETAKIMAB DECREASES DISEASE ACTIVITY IN PATIENTS WITH PSORIATIC ARTHRITIS: RESULTS FROM A RANDOMIZED DOUBLE-BLIND PHASE 3 CLINICAL TRIAL (PATERA)}

T. Korotaeva ${ }^{1}$, I. Gaydukova ${ }^{2}$, V. Mazurov ${ }^{2}$, A. Samtsov ${ }^{3}$, V. Khayrutdinov ${ }^{3}$, A. Bakulev ${ }^{4}$, M. Kokhan ${ }^{5}$, A. Kundzer ${ }^{6}$, N. Soroka ${ }^{7}$, E. Dokukina ${ }^{8}$, A. Eremeeva ${ }^{8}$ ${ }^{1}$ Nasonova Research Institute of Rheumatology, Moscow, Russian Federation; ${ }^{2}$ Mechnikov North-Western State Medical University, St-Petersburg, Russian Federation; ${ }^{3}$ Kirov Military Medical Academy, St-Petersburg, Russian Federation; ${ }^{4}$ Razumovsky Saratov State Medical University, Saratov, Russian Federation; ${ }^{5}$ Ural Research Institute of Dermatovenereology and Immunopathology, Ekaterinburg, Russian Federation; ${ }^{6}$ Healthcare Institution Municipal Clinical Hospital No. 1, Minsk, Belarus; ${ }^{7}$ Scientific and Practical Center of Surgery, Transplantology and Hematology, Minsk, Belarus; ${ }^{8} \mathrm{JSC}$ BIOCAD, St-Petersburg, Russian Federation

Background: Netakimab (NTK) is a humanized anti-interleukin 17A antibody approved for the treatment of moderate-to-severe plaque psoriasis.

Objectives: To determine the efficacy and safety of NTK in patients (pts) with active psoriatic arthritis (PsA), based on 24-week (Wk) data from an ongoing phase 3 study (NCT03598751, PATERA).

Methods: 194 eligible adult pts with PsA (CASPAR, 2006) with inadequate response to csDMARD or one TNFi, were randomized (1:1) to receive NTK $120 \mathrm{mg}$ or placebo (PBO) subcutaneously at Wk $0,1,2,4,6,8,10,14,18,22.84$ pts from PBO arm who did not meet ACR20 (20\% improvement of the American College of Rheumatology criteria) by Wk 16 were switched to NTK $120 \mathrm{mg}$. The primary endpoint was ACR20 at Wk 24. DAPSA (Disease Activity Index for Psoriatic Arthritis), the proportion of pts achieved ACR50/70, minimal disease activity (MDA) $(\geq 5 / 7$ MDA criteria) and Psoriatic arthritis response criteria (PSARC) were also analyzed. Results: Baseline demographics and disease characteristics were similar across treatment arms (Table 1). 80 (82.47\%) pts in NTK arm and 9 (9.28\%) in the PBO arm achieved ACR20 at Wk $24(p<0.0001)$. A significantly greater percentage of NTK-treated pts had ACR50/70, PsARC response, MDA at Wk 24 (Figure 1). By Wk 24 DAPSA significantly improved for NTK vs PBO. DAPSA remission was achieved by $36.08 \%$ and $13.40 \%$ in NTK and PBO arms, respectively $(p=0.003)$. NTK was well tolerated. The most frequent AEs $(\geq 3 \%)$ were lymphopenia, neutropenia, hypercholesterolemia, ALT increased, upper respiratory tract infection, systolic blood pressure increased, hyperglycemia, hyperbilirubinemia. Most AEs were mild to moderate. Severe treatment-related AEs were observed in $1.03 \%$ vs $2.06 \%$ for NTK and PBO, respectively. No treatment-related SAEs were reported. No anti-drug antibodies were detected.

Table 1. Baseline demographics and disease severity characteristics

\begin{tabular}{lcc}
\hline Arm & NTK $(\mathbf{N}=97)$ & PBO (N=97) \\
\hline Age (years) * & $44.0(11.66)$ & $43.1(11.88)$ \\
Male, n (\%) & $52(53.61)$ & $50(51.55)$ \\
PsA duration, mo* & $63.1(73.12)$ & $68.2(77.49)$ \\
DAS28-CRP* $^{*}$ & $4.62(0.97)$ & $4.41(1.11)$ \\
DAPSA & $32.19(12.23)$ & $33.54(15.98)$ \\
TJC (66/68) & $12.9(9.97)$ & $12.0(9.88)$ \\
SJC (66/68) & $7.0(4.93)$ & $7.2(7.18)$ \\
MTX at baseline & $83(85.6)$ & $83(85.6)$ \\
Previous PsA therapy & & $11(11.34)$ \\
Sulfasalazine, n (\%) & $9(9.28)$ & $8(8.25)$ \\
Leflunomide, n (\%) & $4(4.12)$ & $17(17.53)$ \\
Anti-TNFa, n (\%) & $22(22.68)$ &
\end{tabular}

* mean (standard deviation); Mo=months, PsA=psoriatic arthritis, SJC=swollen joint count, TJC=tender joint count, DAS28=Disease Activity Score, MTX=methotrexate, CRP=C-reactive protein, DAPSA=Disease activity index for psoriatic arthritis, TNF=tumor necrosis factor 


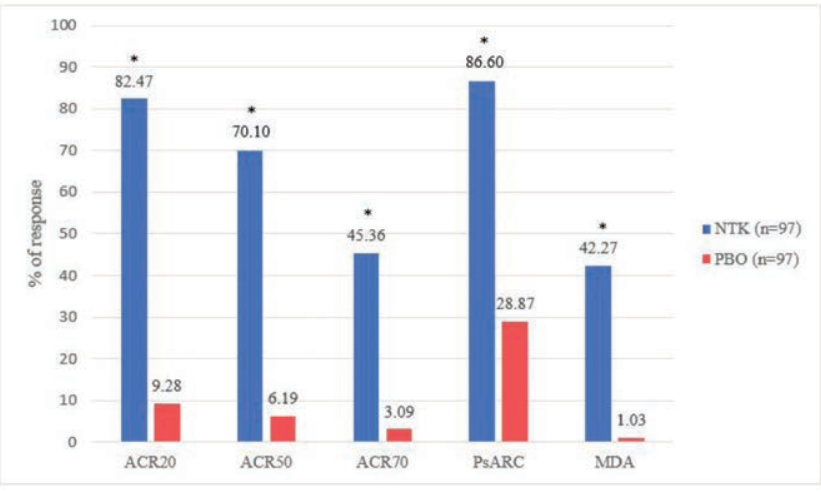

${ }^{*} \mathrm{p}<0.0001$ for comparison with placebo

Figure 1. Treatment response at Wk 24

Conclusion: NTK is a well-tolerated monoclonal antibody, that provided sustained improvements in signs and symptoms of active PsA through 24 Wks of therapy.

\section{Table 2. Safety data}

\begin{tabular}{lccc}
\hline Arm & NTK $(\mathrm{N}=97)$ & PBO $(\mathrm{N}=97)$ & p-value \\
\hline Treatment-related AEs & $12(12.37)$ & $7(7.22)$ & $0.227^{1}$ \\
Treatment-related SAEs & $0(0)$ & $0(0)$ & $1.00^{2}$ \\
Treatment-related AEs (grade 3-4) & $1(1.03)$ & $2(2.06)$ & $1.00^{2}$ \\
Local reactions & $0(0)$ & $0(0)$ & - \\
$\begin{array}{l}\text { Grade 3-4 treatment-related AEs } \\
\text { blood pressure increased }\end{array}$ & $1(1.03)$ & $0(0)$ & $1.00^{2}$ \\
lymphopenia & $0(0)$ & $2(2.06)$ & $0.497^{2}$ \\
\end{tabular}

$\mathrm{n}(\%)$ are presented, ${ }^{1}$ Pearson's $\mathrm{x}^{2}$ test, ${ }^{2}$ Fisher's exact test; $\mathrm{N}=$ number of patients, $\mathrm{AE}=$ adverse event, $\mathrm{SAE}=$ serious adverse event, $\mathrm{ALT}=\mathrm{Alanine}$ transaminase

Acknowledgments: This study was sponsored by JSC BIOCAD.

Disclosure of Interests: Tatiana Korotaeva Consultant of: Pfizer, MSD, Novartis, AbbVie, Celgene, JSC BIOCAD, Janssen, UCB, Lilly and Novartis-Sandoz, Speakers bureau: Pfizer, MSD, Novartis, AbbVie, Celgene, JSC BIOCAD, Janssen, UCB, Lilly and Novartis-Sandoz, Inna Gaydukova Grant/research support from: JSC BIOCAD, Speakers bureau: Pfizer, Novartis, AbbVie, JSC BIOCAD, Celgene, MSD, Sanofi, V Mazurov: None declared, Aleksey Samtsov Grant/ research support from: JSC BIOCAD, Novartis, Eli Lilly, Johnson\&Johnson, Celgene, Glenmark, Galderma, Sanofi, Vladislav Khayrutdinov Grant/research support from: Akrikhin, Alkoy, Belupo, JSC BIOCAD, Bosnaliejk, Verteks, Glenmark, Elfa, Leo Pharma, MSD, Novartis, Pfizer, Sun Pharma, Sanofi, Celgene, Pharmtec, AbbVie, Eli Lilly, Jadran, Janssen, Andrey Bakulev Grant/research support from: AbbVie, Eli Lilly, Pfizer, UCB, MSD, Novartis, Galderma, Celgene, Leo Pharma and Johnson\&Johnson, JSC BIOCAD, Consultant of: Novartis, Celgene and Johnson\&Johnson, Speakers bureau: AbbVie, Eli Lilly, Galderma, UCB, Novartis, Celgene and Johnson\&Johnson, Muza Kokhan Grant/research support from: AbbVie, Eli Lilly, Pfizer, UCB, MSD, Novartis, Galderma, Celgene, Leo Pharma and Johnson\&Johnson, JSC BIOCAD, Consultant of: Novartis, Celgene and Johnson\&Johnson, Speakers bureau: AbbVie, Eli Lilly, Galderma, UCB, Novartis, Celgene and Johnson\&Johnson, Alena Kundzer: None declared, Nikolaj Soroka Grant/research support from: JSC BIOCAD, Ekaterina Dokukina Employee of: JSC BIOCAD, Anna Eremeeva Employee of: JSC BIOCAD DOI: 10.1136/annrheumdis-2020-eular.3469

\section{OP0227 SECUKINUMAB VERSUS ADALIMUMAB HEAD-TO- HEAD COMPARISON IN BIOLOGIC-NAÏVE PATIENTS WITH ACTIVE PSORIATIC ARTHRITIS THROUGH 52-WEEKS (EXCEED): A RANDOMISED, DOUBLE- BLIND, PHASE-3B STUDY}

I. Mcinnes ${ }^{1}$, F. Behrens ${ }^{2}$, P. J. Mease ${ }^{3}$, A. Kavanaugh ${ }^{4}$, C. T. Ritchlin ${ }^{5}$, P. Nash ${ }^{6}$, J. Gratacos-Masmitja ${ }^{7}$, P. Goupille ${ }^{8}$, T. Korotaeva ${ }^{9}$, A. B. Gottlieb ${ }^{10}$, R. Martin ${ }^{11}$, K. Ding ${ }^{11}$, P. Pellet ${ }^{12}$, S. Mpofu ${ }^{12}$, L. Pricop ${ }^{11} .{ }^{1}$ University of Glasgow, Glasgow, United Kingdom; ${ }^{2}$ Rheumatology University Hospital, Frankfurt, Germany;

${ }^{3}$ Swedish Medical Centre, Seattle, United States of America; ${ }^{4}$ UCSD, La Jolla, United States of America; ${ }^{5}$ University of Rochester, Rochester, United States of America; ${ }^{6}$ Griffith University, Brisbane, Australia; ${ }^{7}$ University Hospital Parc Tauli, Sabadell, UAB, Spain; ${ }^{8}$ University of Tours, Tours, France; ${ }^{9}$ Research Institute of Rheumatology n.a. V.A. Nasonova, Moscow, Russian Federation; ${ }^{10}$ Icahn School of Medicine at Mount Sinai, New York, United States of America; ${ }^{11}$ Novartis
Pharmaceuticals Corporation, East Hanover, United States of America;

${ }^{12}$ Novartis Pharma AG, Basel, Switzerland

Background: Secukinumab (SEC), an interleukin-17A inhibitor, has demonstrated improvements on multiple domains of psoriatic arthritis (PsA). ${ }^{1}$ Adalimumab (ADA), a TNF inhibitor, is widely used as a first-line biologic in PsA.

Objectives: To report efficacy and safety outcomes from the head-to-head EXCEED trial (NCT02745080) that compares SEC vs. ADA as first-line biologic monotherapy through 52-weeks (wks), with a musculoskeletal primary endpoint in pts with active PsA.

Methods: Head-to-head, phase-3b, randomised, double-blind trial: biologic naïve active PsA pts were randomised to receive SEC $300 \mathrm{mg}$ subcutaneous at baseline, Wk1-4, and then every 4wks (q4w) until Wk48 or ADA 40mg subcutaneous at baseline and then q2w until Wk50. The primary endpoint was superiority of SEC vs. ADA on ACR20 response at Wk52. Binary and continuous variables were analysed using logistic-regression model and MMRM, respectively. Safety analysis included patients who received $\geq 1$ dose of study-drug.

Results: 853 pts were randomised to receive SEC $(n=426)$ or ADA $(n=427)$. Baseline demographics and disease characteristics were comparable between treatment-groups except higher proportion of female pts and pts without enthesitis in the SEC group. ACR20 response at Wk52 for SEC vs. ADA were $67.4 \%$ vs. $61.5 \%$, respectively $(\mathrm{p}=0.0719)$ (Figure). Higher clinical responses were observed with SEC vs. ADA for a range of musculoskeletal, skin, and higher-hurdle outcomes (Table). A higher retention rate was observed for SEC (85.7\%) vs. ADA $(76.3 \%)$. Safety profiles of SEC and ADA were consistent with previous reports. ${ }^{2,3}$

Conclusion: Results suggest that SEC is at least as efficacious as ADA on musculoskeletal endpoints whilst providing higher responses on skin endpoints, and is associated with a higher retention rate. No new safety signals were reported. References:

[1] van der Heijde, et al. Rheumatol. (Oxford).2019; DOI10.1093/rheumatology/ kez420.

[2] Deodhar A, et al. Arthritis Res Ther. 2019;21:111.

[3] Burmester GR, et al. Ann Rheum Dis.2013; 72:517-24.

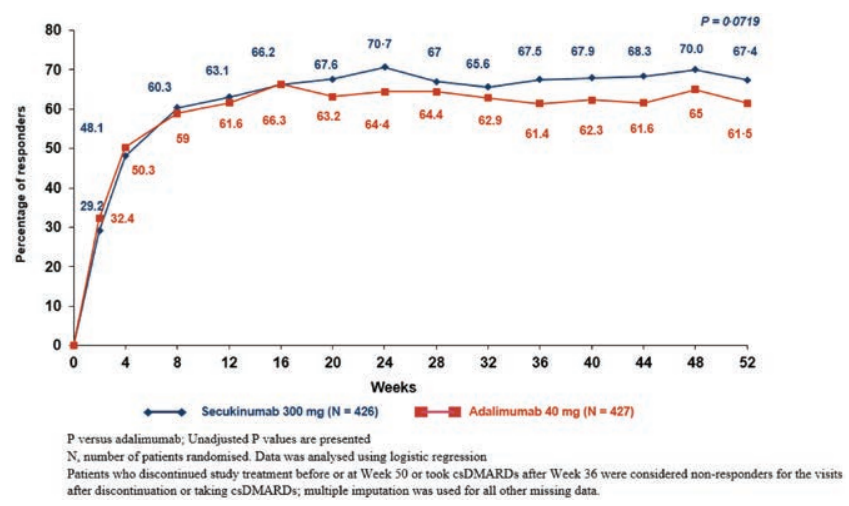

Figure. ACR20 Response through Wk 52

Table. Efficacy Outcomes at Wk 52

\begin{tabular}{lccc}
\hline $\begin{array}{l}\text { Endpoints, \% response unless specified } \\
\text { otherwise }\end{array}$ & $\begin{array}{c}\text { SEC } 300 \mathrm{mg} \\
(\mathrm{N}=426)\end{array}$ & $\begin{array}{c}\text { ADA 40 mg } \\
(\mathrm{N}=427)\end{array}$ & $\begin{array}{c}\text { P-value } \\
\text { (unadjusted) }\end{array}$ \\
\hline ACR20 & 67.4 & 61.5 & 0.0719 \\
aACR20 & 66.9 & 59.5 & 0.0239 \\
Key Secondary & 65.4 & 43.2 & $<0.0001$ \\
bPSI 90 & 49.0 & 44.8 & 0.2251 \\
ACR50 & $-0.58 \pm 0.03$ & $-0.56 \pm 0.03$ & 0.5465 \\
HAQ-DI mean change from baseline \pm SE & 60.5 & 54.2 & 0.1498 \\
${ }^{c}$ Resolution of enthesitis (based on LEI) & & & \\
Exploratory & 43.0 & 37.9 & 0.1498 \\
MDA & 18.1 & 16.6 & 0.6107 \\
VLDA & 61.7 & 53.1 & 0.0178 \\
DAPSA LDA+Remission & 51.1 & 44.1 & 0.0557 \\
PASDAS LDA+Remission & & &
\end{tabular}

*Unadjusted P-values vs ADA

Binary variables were analysed using logistic regression. Pts who discontinued study treatment prematurely or took csDMARDs after week- 36 were considered non-responders. Multiple imputation was used for all other missing data. HAQ-DI mean change from baseline was analysed using mixed-effect model repeated measures

${ }^{a}$ Non-responder imputation was used for pre-specified sensitivity analysis

${ }^{\mathrm{b}} \mathrm{N}=215$ in SEC and $\mathrm{N}=202$ in ADA in psoriasis subset

${ }^{\mathrm{c}} \mathrm{N}=234$ in SEC and $\mathrm{N}=264$ in ADA in enthesitis subset 